\title{
Lamellar macular hole associated with idiopathic juxtafoveolar telangiectasia
}

\author{
B PATEL,' J DUVALL, ${ }^{2}$ AND A B TULLO
}

From 'Moorields Eye Hospital, City Road, London EC; the '2Department of Ophthalmology, University of Manchester; and ${ }^{3}$ Manchester Royal Eye Hospital

SUMmaRY A case of juxtafoveolar telangiectasia complicated by lamellar, retinal hole is reported and the pathogenesis discussed. This association is not commonly recognised.

Idiopathic juxtafoveolar telangiectasia is a relatively rare condition predominantly affecting adult males. ${ }^{\prime}$ Visual disturbance in retinal telangiectasia is usually due to vascular leakage, with intraretinal oedema and exudate accummulation and later cystic degeneration.' Subretinal neovascularisation with a disciform response may also contribute to a poor visual outcome. In this report we describe a case of unilateral idiopathic juxtafoveolar telangiectasia with central visual loss due to a lamellar macular hole.

\section{Case report}

A 37-year-old Caucasian was found in the course of a routine eye test to have a central visual acuity of $6 / 18$ in the left eye. The visual acuity in the right eye was $6 / 5$. Both anterior segments were normal, as was the right fundus. There was an incomplete ring of circinate exudate round the left fovea, with a lamellar hole at the fovea (Fig. 1).

The patient was in good general health and in particular was not diabetic or hypertensive. An oral glucose tolerance test was normal. There was no history of ocular trauma, inflammation, or vascular disease.

Fluorescein angiography showed a cluster of telangiectatic vessels at the centre of the exudate, and a smaller area of telangiectatic vessels inferotemporal to the lamellar hole (Fig. 2). There were widespread but discontinuous areas of telangiectatic vessels in all peripheral quadrants. The larger area of abnormal vessels was treated with argon laser, which

Correspondence to Josephine Duvall, FRCS Ed, Department of Ophthalmology, Manchester Royal Eye Hospital, Oxford Road, Manchester M13 9WH. brought about a significant diminution of hyperfluorescence on angiography but had no effect on the exudate or the visual acuity over the five-month follow-up period.

\section{Discussion}

The term idiopathic retinal telangiectasia was proposed by Reese ${ }^{2}$ to define a spectrum of congenital vascular anomalies which includes Coats' disease, Leber's miliary aneurysms, and juxtafoveolar telangiectasia. These are to be distinguished from secondary forms of telangiectasia associated with branch vein occlusion, diabetes mellitus, sickle cell retinopathy, carotid artery occlusion, and radiation retinopathy.

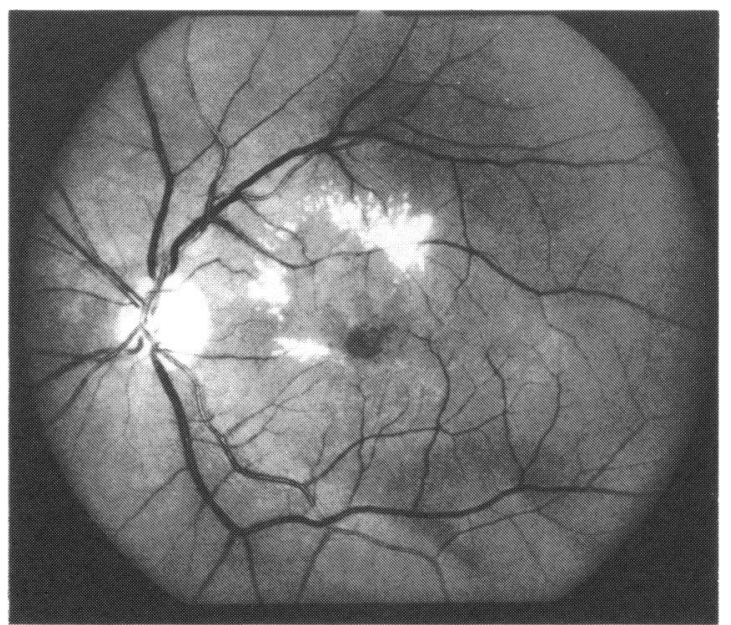

Fig. 1 Fundus photograph showing lamellar macular hole with circinate exudate. 


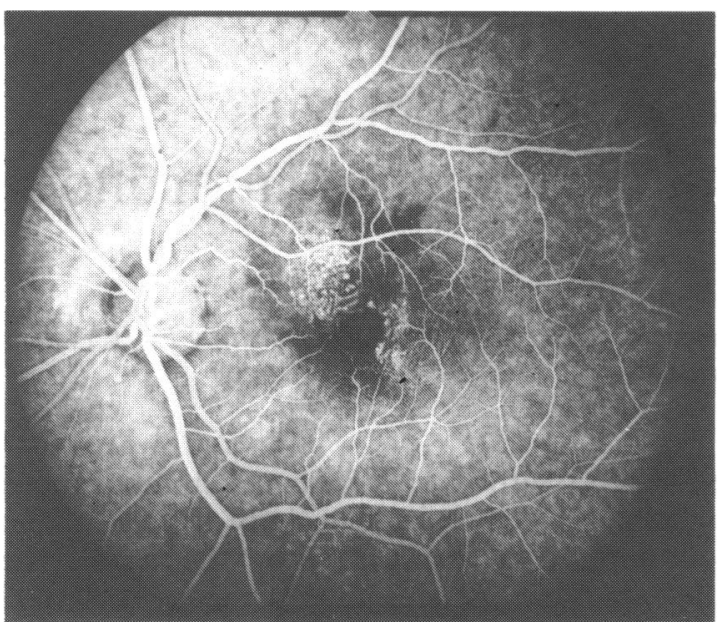

Fig. 2 Fluorescein angiogram showing two areas of vascular telangiectasis, one superonasal and the other inferotemporal to the fovea.

Gass and Oyakawa ${ }^{3}$ reported the findings in a series of 27 cases of idiopathic juxtafoveolar telangiectasia and classified the condition into four groups. The first group, into which our patient loosely fits, comprised eight males and was characterised by uniocular involvement, with telangiectasia confined to the temporal half of the macula, symmetrically distributed above and below the horizontal raphe. Visual loss was a consequence of macular oedema. In the other three groups both eyes were affected, and the cause of visual loss was subretinal neovascularisation as well as macular oedema. In the series there were no cases with macular hole in group 1 , but in the other groups there was one patient who developed a macular hole and one case of retinal thinning. In a series of 46 cases reported recently by Casswell and colleagues ${ }^{4}$ no macular holes were seen.

We are aware of only two other case reports of macular hole associated with retinal telangiectasia. One of these is in a case of Coats' disease ${ }^{5}$ and the other in a histopathological review of macular holes. ${ }^{6}$

Macular holes most commonly occur as a sequel to macular oedema. ${ }^{67} \mathrm{We}$ are surprised that they have not been more frequently found in association with telangiectatic lesions, since it appears beyond dispute that leakage from the abnormal vessels causes intraretinal oedema. This might be expected to induce local destruction of the retina with the formation of cysts and ultimately holes.

We could speculate that in unilateral idiopathic retinal telangiectasia the lesion is largely limited to the locally involved vessels, whereas in other forms of macular oedema the retina itself is affected by a more widespread circulatory or haemodynamic abnormality giving rise to the oedema. In the latter case there may be less resistance from compromised tissues to intraretinal fluid destroying adjacent structures, forming cysts and ultimately holes. In unilateral cases with no widespread defect the more healthy adjacent areas of retina may maintain their architecture in the presence of oedema fluid. Both the case showing the macular hole and that showing retinal thinning in the series were in the bilateral groups.

Only in bilateral cases in the series of Gass and Oyakawa $^{3}$ was subretinal neovascularisation or a disciform response seen. This may be interpreted as an indication of more generalised retinal disturbance, probably of ischaemic nature, rather than the localised vascular malformation of unilateral cases. Our hypothesis fits with the findings recently reported by Casswell et al., ${ }^{4}$ who suggest that unilateral disease is indicative of a vascular abnormality, whereas bilateral disease may indicate a pigment epithelial defect.

Recently it has been reported that abnormalities of glucose tolerance may be found in cases previously diagnosed as idiopathic juxtafoveal telangiectasia. ${ }^{{ }}$ Among 28 patients five out of eight bilateral cases had abnormal glucose tolerance, while only six out of 17 unilateral cases showed any abnormality. These results give some support to the hypothesis that bilateral disease occurs in relation to a widespread metabolic disturbance in the retina, whereas unilateral cases represent a local and truly vascular defect.

We would then expect macular holes to occur more frequently in association with secondary retinal telangiectasis. This hypothesis will be investigated.

\section{References}

1 Gitter KA, Yanuzzi LA, Schatz H. Retinal telangiectasia. In: Yanuzzi LA, Gitter KA, Schatz H. The macula: a comprehensive text and atlas. Baltimore: Williams and Williams, 1979: 118-26.

2 Reese AB. Telangiectasia of the retina and Coats' disease. $A m \mathrm{~J}$ Ophthalmol 1956; 42: 1-8.

3 Gass JD, Oyakawa RT. Idiopathic juxtafoveolar retinal telangiectasia. Arch Ophthalmol 1982; 100: 769-80.

4 Casswell AG, Chaine L, Rush P, Bird AC. Paramacular telangiectasia. Trans Ophthalmol Soc UK 1986; 105: 683-92.

5 Bengisi N. Coats' disease and a macular hole. Ann Oculist (Paris) 1968; 201: 158-62.

6 Frangieh GT, Green WR, Engel HM. A histopathologic study of macular cysts and holes. Retina 1981; 1: 311-36.

7 Aaberg TM. Macular holes: a review. Surv Ophthalmol 1970; 15: 139-62.

8 Millay RH, Klein ML, Handelman IL, Watzke RC. Abnormal glucose metabolism and parafoveal telangiectasia. Am J Ophthalmol 1986; 102: 363-70.

Accepted for publication 1 May 1987. 